EGU21-11192, updated on 06 May 2021

https://doi.org/10.5194/egusphere-egu21-11192

EGU General Assembly 2021

(c) Author(s) 2021. This work is distributed under

the Creative Commons Attribution 4.0 License.

\title{
The unit peak discharge as a tool for flood magnitude comparison and analysis
}

\author{
Josep Carles Balasch ${ }^{1}$, Jordi Tuset ${ }^{1}$, Mariano Barriendos ${ }^{2}$, Xavier Castelltort ${ }^{1}$, and David Pino ${ }^{3,4}$ \\ ${ }^{1}$ Department of Environment and Soil Sciences, University of Lleida, Lleida, Spain \\ ${ }^{2}$ Department of History and Archaeology, University of Barcelona, Barcelona, Spain \\ ${ }^{3}$ Department of Physics. Universitat Politècnica de Catalunya (UPC)-Barcelona Tech, Castelldefels, Spain \\ ${ }^{4}$ Institute of Space Studies of Catalonia (CTA-UPC), Barcelona, Spain
}

To analyze the river floods dynamics, it is common to fix the observations of the flow at a characteristic checkpoint of the basin, showing its evolution over time: the hydrograph. A less common way of studying this hydrological phenomenon is the analysis of the unit peak discharge of the flood (i.e., the peak flow divided by the contributory area of the basin) along different checkpoints of the drainage axis.

If this second methodology is chosen for the analysis of the river flooding, the circulation of flows through the river network generally shows that as the contributory area of the basin increases the unit peak discharge decreases. This is due to the reduction in the amount of precipitation and the slope of the riverbed with the increase of the basin area as it moves away from the headwaters. However, this simple scheme can have very different behavior depending on factors such as the spatial and temporal distribution of precipitation, the presence of snow, the soil moisture, the geological substrate, land uses, or human activities.

This study compares the hydrological data of several historical and recent floods in NE basins of the Iberian Peninsula from the perspective of observing the unit peak flows depending on the size of the drained basin (i.e., the spatial evolution of the specific maximum discharge). These basins are small in size (usually below $500 \mathrm{~km}^{2}$ ) and drain regions such as the central Pyrenees (Garonne, Noguera Pallaresa), the Ebro Depression (rivers Ribera Salada, Sió, Ondara, Corb) and the Catalan Coastal System (Francolí), that is, they belong to very diverse geographical environments.

The results allow to compare the magnitude of the unit peak flows in the headwaters and the decreasing of this variable when moving downstream. The unit peak discharges of the tributaries of the Ebro Depression, near the Catalan Coastal System are much higher when comparing with the flow of the Pyrenean rivers. For many floods of the Ebro basin of medium magnitude, the unit peak flow is reduced by the runoff infiltration in the flood plains favored by agricultural activities. In the Pyrenean rivers the spatial decrease of the unit peak discharge is gentle than in those of the Ebro Depression. The results show different patterns of flow generation and propagation that have implications for managing the dangerousness of flood risk, especially in very small basins (< $10 \mathrm{~km}^{2}$ ), where peak flows can be unexpectedly large and devastating. 
